\title{
Characterization of an isophorone-based polyisocyanate
}

\author{
Fabrice Burel ${ }^{1}$, Adeline Feldman ${ }^{1}$, Corinne Loutelier-Bourhis ${ }^{2}$, Claude Bunel ${ }^{1}$ * \\ ${ }^{1}$ Laboratoire de Matériaux Macromoléculaires, UMR CNRS 6522, PBM, INSA de \\ Rouen, BP 08, place Emile Blondel, 76131 Mont-Saint-Aignan cedex, France; \\ Fax 33-02.35.52.84.46; fabrice.burel@insa-rouen.fr, claude.bunel@insa-rouen.fr \\ ${ }^{2}$ Laboratoire de Spectrométrie de Masse Bio-Organique, UMR CNRS 6014, \\ Université de Rouen, 76821 Mont-Saint-Aignan cedex, France
}

(Received: February 3, 2004; published: February 25, 2004)

\begin{abstract}
After chemical modification with methanol, a polyisocyanate based on the isocyanurate of isophorone diisocyanate was analysed. MALDI-TOF MS and sizeexclusion chromatography were chosen and indirectly coupled to identify and quantify the different species. While, as expected, the isocyanate trimer and pentamer are the two main components, homologues until the tridecamer could be identified with MS. Moreover, the isocyanurate cycle occurs preferentially on the primary isocyanate group. According to the calculated composition, a numberaverage molecular weight of 775 and a number-average isocyanate functionality of 3,24 were determined.
\end{abstract}

\section{Introduction}

Polyurethane elastomers are a class of polymeric materials showing a wide range of interesting physical and mechanical properties such as tensile properties, thermal behaviour, hardness, and surface characteristics. These properties are essentially linked to the nature of the polyol (polyester, polyether, ...) and of the isocyanate. In the coating industry both aromatic and aliphatic isocyanates are used. Nevertheless, compared to the aromatic structures, coatings based on aliphatic isocyanate exhibit excellent light and weather stability and are, therefore, usually used for outdoor applications. Among the most common aliphatic isocyanates are hexamethylene diisocyanate (HDI) and isophorone diisocyanate (IPDI). The major problem encountered with these products is their high volatility, which enhances the inherent toxicity of the isocyanate group. To avoid this drawback, the coating industry works with trimerized diisocyanates leading to biuret or isocyanurate forms (Scheme 1). Both are less toxic and enhance thermal properties compared to the corresponding diisocyanates. However, the trimerization processes used to obtain biuret and isocyanurate products often yield mixtures of polymeric forms [1].

While IPDI has been previously characterized [2,3], this is not the case for the corresponding isocyanurate, in spite of its growing use for outdoor applications. Its characterization is, therefore, necessary for a further understanding and optimization of the isocyanurate - alcohol reaction. In this paper, an IPDI isocyanurate is studied with a combination of analytical techniques including size-exclusion chromatography (SEC), 
${ }^{13} \mathrm{C}$ NMR and mass spectrometry using matrix-assisted laser desorption ionization (MALDI-TOF MS).

Isocyanurate:

$3 \mathrm{OCN}-\mathrm{R}-\mathrm{NCO}$

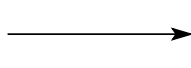<smiles></smiles>

Biuret:<smiles>O=COC(=O)[W]=O</smiles><smiles>[R]N[Y]([H])([H])NC(=O)N([R]N[N+](=O)[O-])C(=O)N[O+]</smiles>

Scheme1. Isocyanurate and biuret formation

\section{Experimental part}

\section{Materials}

IPDI isocyanurate (Vestanat 1890/100) was kindly supplied by Degussa-Hüls. According to the supplier this product has an average molar mass of $825 \mathrm{~g} / \mathrm{mol}$ and $\% \mathrm{NCO}=16 \pm 1$. Methanol (RPE, Carlo Erba) was used as received. $\alpha$-Cyano-4hydroxycinnamic acid (CHCA), acrylonitrile and tetrahydrofuran used for MALDI-TOF MS were purchased from Sigma.

Neutralization of the isocyanate functions<smiles></smiles>

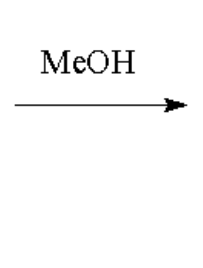<smiles>[R]Nn1c(=O)n([R]([H])NC(C)=O)c(=O)n([R]([H])NC(C)=O)c1=O</smiles><smiles>CCC1(C)CC(C)CC(C)(C)C1</smiles>

Scheme 2. IPDI isocyanurate neutralization with methanol. The reaction media was refluxed for $120 \mathrm{~h}$

Methanol (50 mL) was added to IPDI isocyanurate pellets (2 $\mathrm{g} ; 7,6$ meq NCO) and stirred to form a uniform solution. The reactants were mixed under reflux for 5 days. The disappearance of the isocyanate band $\left(2270 \mathrm{~cm}^{-1}\right)$ was verified via FTIR spectroscopy. Excess of methanol was then removed in vacuum to obtain the neutralized product. 


\section{Mass spectrometry}

The essential principle of TOF-MS is that ions of different masses but of constant kinetic energy (subjected to the same acceleration voltage) move in the same direction in a free field region up to a detector with different velocities inversely proportional to the square root of $\mathrm{m} / \mathrm{z}$. In our case, MALDI-TOF MS experiments were acquired on a Tof-Spec E mass spectrometer (Micromass, Manchester, UK) equipped with a nitrogen laser (emission wavelength at $337 \mathrm{~nm}$, pulse duration $4 \mathrm{~ns}$ ). Spectra were recorded in positive ion mode using $20 \mathrm{kV}$ acceleration voltage, delayed extraction (600 ns) and reflectron mode. In such mode, the measurements lead to the monoisotopic masses of the molecular ions. External calibration was carried out using the molecular ions of leucine-enkephalin, substance $P$, neurotensin and ACTH (fragment 18-39). Each spectrum was recorded by accumulating data from 50 laser shots.

Samples were first diluted in $\mathrm{CH}_{3} \mathrm{CN}$, and then another dilution in $\mathrm{CH}_{3} \mathrm{CN} / \mathrm{H}_{2} \mathrm{O}$ with 20 $\mathrm{mM} \mathrm{NaCl}$ (factor 100) was performed. MALDI targets were prepared using a-cyano4-hydroxycinnamic acid (CHCA) as the matrix and the dried droplet method: $1 \mu \mathrm{L}$ of the diluted sample was mixed with $1 \mu \mathrm{L}$ of the matrix solution $\left(10 \mathrm{mg} / \mathrm{mL}\right.$ in $\mathrm{CH}_{3} \mathrm{OH} /$ $\mathrm{CH}_{3} \mathrm{CN}$ ). Then, $1 \mu \mathrm{L}$ of the mixture was deposited on the MALDI target and allowed to dry in vacuum. CHCA was chosen because it appeared to be the more appropriate matrix for a decent signal-to-noise ratio in case of IPDI isocyanurate samples even if some matrix clusters could be detected.

\section{Size exclusion chromatography}

Separations were obtained with a Spectra Series P100 pump using $5 \mu$ columns (Phenomenex $100 \AA, 500 \AA$ and PL Gel Mixed C) with THF as eluent at a flow rate of

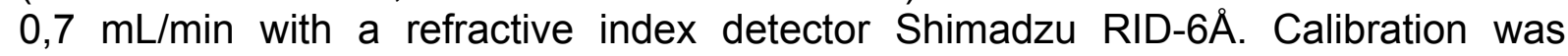
conducted using polystyrene standards.

\section{Results and discussion}

All experiments were carried out on the neutralized sample of IPDI to avoid any eventual side reaction inherent to the isocyanate group (Scheme 2). First, sizeexclusion chromatography was applied. The separation shows that the sample is a mixture of five components (Fig. 1).

The main peak 1 should correspond to the neutralized trimer $\left(I_{1}\right)$ while the following peaks could be assigned to higher homologues (Scheme 3 ). By analogy with the study of $\mathrm{Ni}$ et al. [4], these should be the pentamer $\left(\mathrm{I}_{2}\right)$, heptamer $\left(\mathrm{I}_{3}\right)$, nonamer $\left(\mathrm{I}_{4}\right.$, $\left.I_{4}{ }_{4}\right)$ and undecamer $\left(I_{5}, I_{5}\right)$ isocyanates. For the nonamer and undecamer components two different structures could be obtained. For example, assuming that each isocyanate group has the same reactivity, statistically the nonamer should be composed of $20 \% \mathrm{I}_{4}$ and $80 \% \mathrm{I}_{4}$ while the undecamer should contain $46,6 \%$ and $53,4 \%$ of $I_{5}$ and $I_{5}$, respectively. Then, the whole sample was subjected to MALDITOF MS, a soft ionization technique, which produces singly charged molecular ions from large, polar and non-volatile compounds. This ionization technique is based on desorption-ionization processes obtained by shooting a crystallized sample of analyte in a suitable matrix with a pulsed laser.

The MALDI spectrum of the commercial IPDI isocyanurate shows sodium adducts $[\mathrm{MNa}]^{+}$of the trimer, pentamer and heptamer isocyanurates at $\mathrm{m} / \mathrm{z} 785,5,1261,8$ and 
1738,0 , respectively. The signal intensity decreases whereas the size of the isocyanurate increases because of (i) the lower concentrations of the heavier compounds, and (ii) reduction of the ion signal with the molecular weight because the detector of the mass spectrometer is velocity-dependent (see Exptl. part). So isocyanurate oligomers higher than heptamer could not be observed.

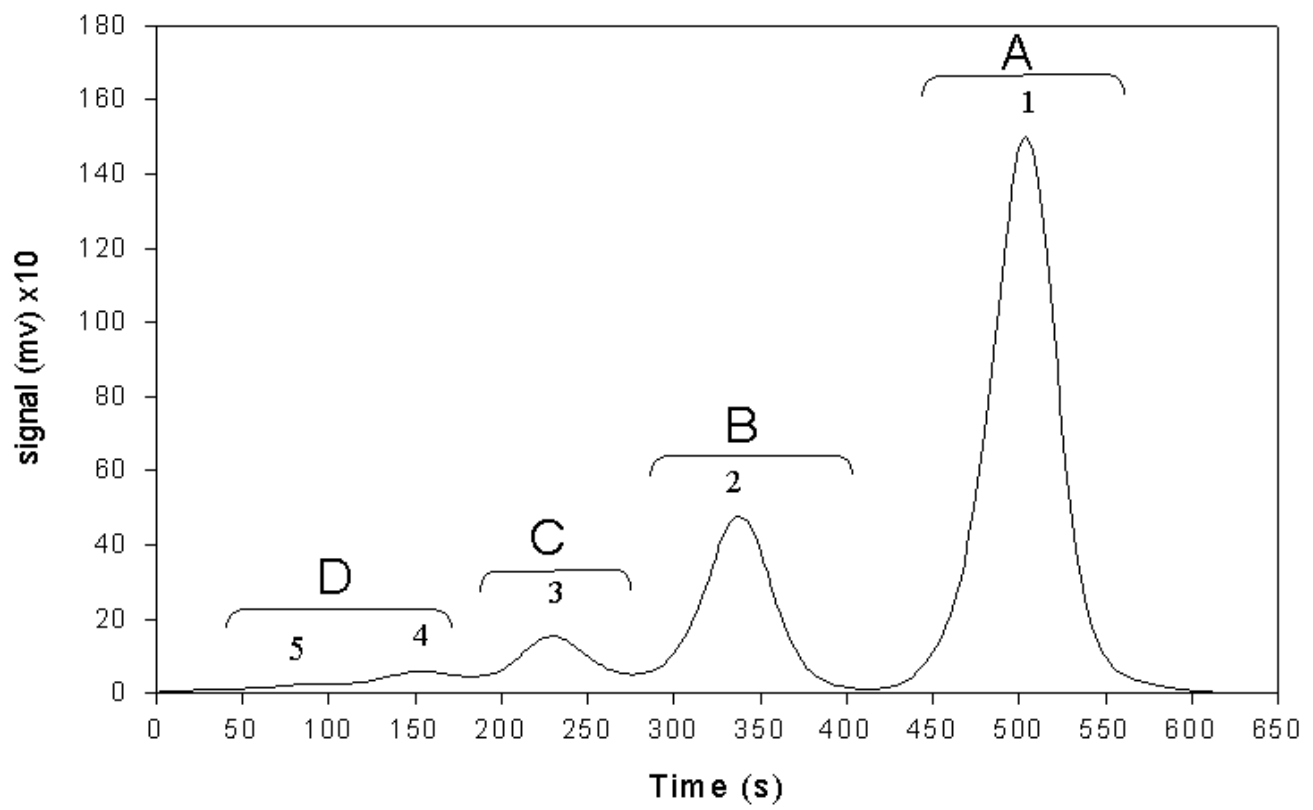

Fig. 1. SEC chromatogram in THF of the whole modified isocyanurate
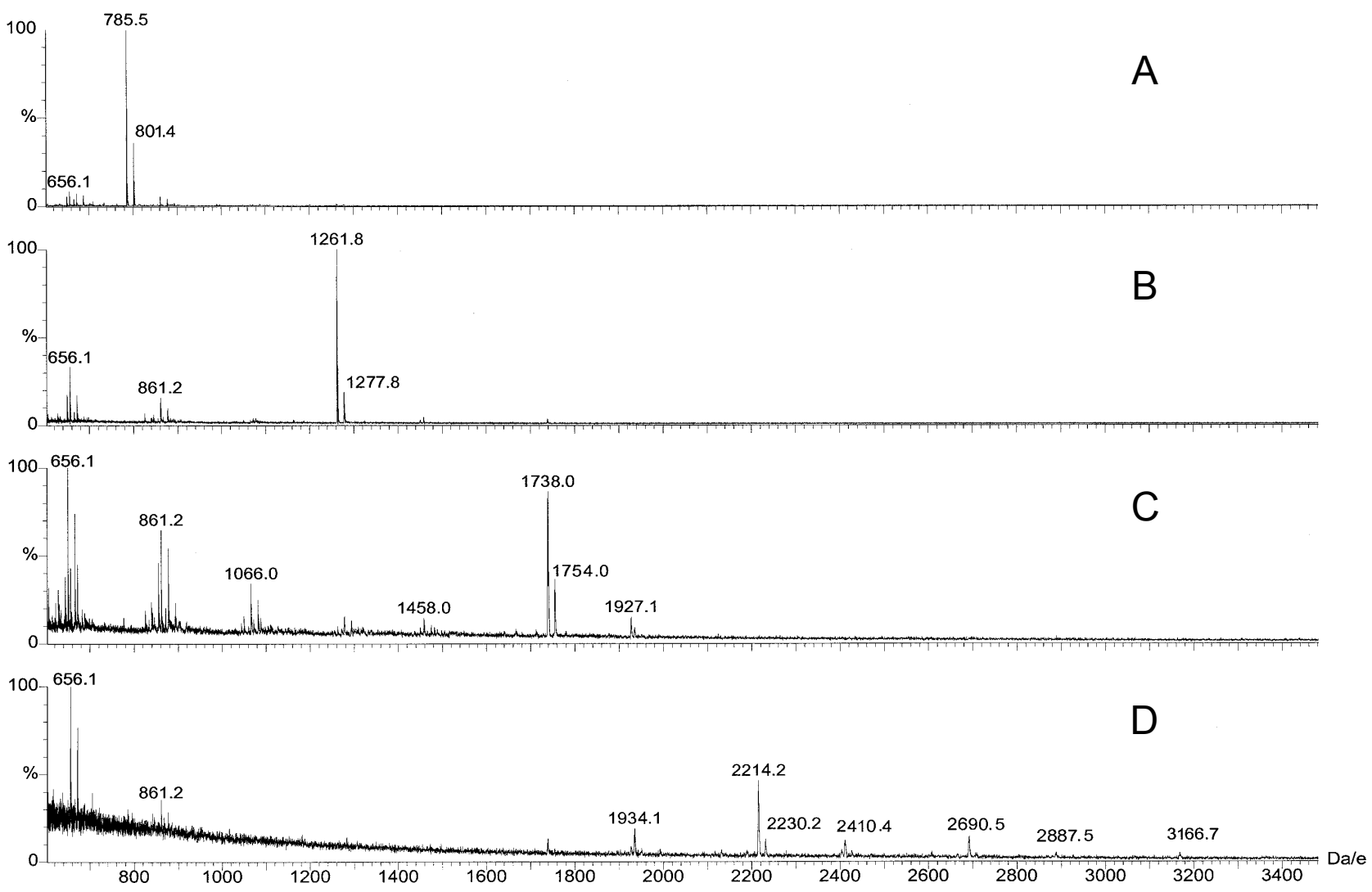

Fig. 2. MALDI mass spectra of the four different fractions $A$ to $D$ of Fig. 1 
To identify all species in IPDI isocyanurate and to assign each chromatographic peak of the SEC analysis, four different fractions (A, B, C and D) from SEC separation (Fig. 1) were collected and analysed via MALDI-TOF MS. The mass spectra of the four collected fractions show the sodium and potassium adducts of the molecular ions (Fig. 2). Thus, the mass spectrum of the first fraction displays ions at $m / z 785,5$ and 801,4 , which are the $\left[{ }_{1} \mathrm{Na}^{+}\right.$and $\left[\mathrm{l}_{1} \mathrm{~K}\right]^{+}$ions of the neutralized isocyanurate trimer $\left(I_{1}\right)$. Likewise, the cationized molecular ions $[\mathrm{MNa}]^{+}$and $[\mathrm{MK}]^{+}$of pentamer $\mathrm{I}_{2}$, heptamer $\mathrm{I}_{3}$ and nonamer $\mathrm{I}_{4}$ are, respectively, observed for the fractions $\mathrm{B}, \mathrm{C}$ and $\mathrm{D}$ at $\mathrm{m} / \mathrm{z}$ 1261,8 and 1277,8 for $I_{2}, 1738,0$ and 1754,0 for $I_{3}, 2214,2$ and 2230,2 for $I_{4}$.

The use of the reflectron mode in MALDI-TOF provides the measurement of the monoisotopic molecular masses. Consequently, the measured $\mathrm{m} / \mathrm{z}$ values are consistent with the theoretical values within 0,02\% (Tab. 1).

Tab. 1. Attribution of the observed $\mathrm{m} / \mathrm{z}$ values of monoisotopic ions

\begin{tabular}{lll}
\hline $\begin{array}{l}\text { Measured } \mathrm{m} / \mathrm{z} \text { of } \\
\text { monoisotopic ions }\end{array}$ & Structural units & $\begin{array}{l}\text { Calculated } \mathrm{m} / \mathrm{z} \text { of } \\
\text { monoisotopic ions }\end{array}$ \\
\hline $785,5\left[\mathrm{I}_{1}, \mathrm{Na}^{+}\right]$ & $3 \mathrm{IPDI}+3 \mathrm{CH}_{3} \mathrm{OH}+\mathrm{Na}^{+}$ & 785,5 \\
$801,4\left[\mathrm{I}_{1}, \mathrm{~K}^{+}\right]$ & $3 \mathrm{IPDI}+3 \mathrm{CH}_{3} \mathrm{OH}+\mathrm{K}^{+}$ & 801,5 \\
$1261,8\left[\mathrm{I}_{2}, \mathrm{Na}^{+}\right]$ & $5 \mathrm{IPDI}+4 \mathrm{CH}_{3} \mathrm{OH}+\mathrm{Na}^{+}$ & 1261,8 \\
$1277,8\left[\mathrm{I}_{2}, \mathrm{~K}^{+}\right]$ & $5 \mathrm{IPDI}+4 \mathrm{CH}_{3} \mathrm{OH}+\mathrm{K}^{+}$ & 1277,8 \\
1458,0 & $6 \mathrm{IPDI}+4 \mathrm{CH}_{3} \mathrm{OH}+\mathrm{Na}^{+}-\mathrm{CO}_{2}+\mathrm{H}_{2} \mathrm{O}$ & 1458,1 \\
$1738,0\left[\mathrm{I}_{3}, \mathrm{Na}^{+}\right]$ & $7 \mathrm{IPDI}+5 \mathrm{CH}_{3} \mathrm{OH}+\mathrm{Na}^{+}$ & 1738,1 \\
$1754,0\left[\mathrm{I}_{3}, \mathrm{~K}^{+}\right]$ & $7 \mathrm{IPDI}+5 \mathrm{CH}_{3} \mathrm{OH}+\mathrm{K}^{+}$ & 1754,1 \\
1934,1 & $8 \mathrm{IPDI}+5 \mathrm{CH}_{3} \mathrm{OH}+\mathrm{Na}^{+}-\mathrm{CO}_{2}+\mathrm{H}_{2} \mathrm{O}$ & 1934,4 \\
$2214,2\left[\mathrm{I}_{4}, \mathrm{Na}^{+}\right]$ & $9 \mathrm{IPDI}+6 \mathrm{CH}_{3} \mathrm{OH}+\mathrm{Na}^{+}$ & 2214,4 \\
$2230,2\left[\mathrm{I}_{4}, \mathrm{~K}^{+}\right]$ & $9 \mathrm{IPDI}+6 \mathrm{CH}_{3} \mathrm{OH}+\mathrm{K}^{+}$ & 2230,4 \\
2410,4 & $10 \mathrm{IPDI}+6 \mathrm{CH}_{3} \mathrm{OH}+\mathrm{Na}^{+}-\mathrm{CO}_{2}+\mathrm{H}_{2} \mathrm{O}$ & 2410,7 \\
$2690,5\left[\mathrm{I}_{5}, \mathrm{Na}^{+}\right]$ & $11 \mathrm{IPDI}+7 \mathrm{CH}_{3} \mathrm{OH}+\mathrm{Na}^{+}$ & 2690,7 \\
2887,5 & $12 \mathrm{IPDI}+7 \mathrm{CH}_{3} \mathrm{OH}+\mathrm{Na}^{+}-\mathrm{CO}_{2}+\mathrm{H}_{2} \mathrm{O}$ & 2887,0 \\
$3166,7\left[\mathrm{I}_{6}, \mathrm{Na}^{+}\right]$ & $13 \mathrm{IPDI}+8 \mathrm{CH}_{3} \mathrm{OH}+\mathrm{Na}^{+}$ & 3167,0
\end{tabular}

Few additional ions are detected in the mass spectra of the four fractions. Some of them are ionic species from the matrix $(\mathrm{m} / \mathrm{z} 656,1,861,2$, and 1066,0, indeed even 1458,0 for the heptamer $I_{3}$ : these clusters do not actually interfere with ionic species from sample compounds and do not prevent the identification of each signal) but others correspond to molecular ions of components present in the IPDI sample. Thus, the weakly abundant ions detected at $\mathrm{m} / \mathrm{z} 2690,5$ and 3166,7 for fraction $\mathrm{D}$ are the sodium adducts of undecamer $I_{5}$ and tridecamer $I_{6}$, respectively. The observation of such oligomers (from pentamer to tridecamer) is explained by further isocyanuration reactions, as already observed for HDI isocyanurate [4] (Scheme 3).

Besides, we can notice ionic species at $m / z$ 1458,0, 1934,1, 2410,4 and 2887,5, which are 196,2 higher than pentamer, heptamer, nonamer and undecamer, respectively. They can result from the reaction with traces of water in the starting diisocyanate leading first to primary amino groups and then to the urea function by 
subsequent condensation reaction with an isocyanate group (Scheme 4). All the assignments listed in Tab. 1 are in agreement with the calculated values.

<smiles>CC1CC(C)(C)CC(C)(C)C1</smiles>

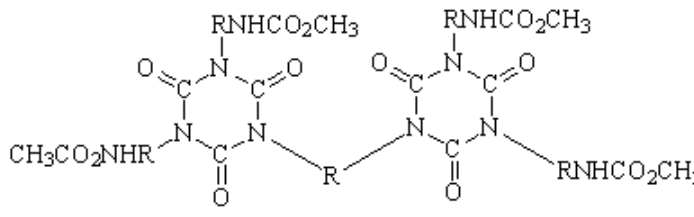



$\left(\mathrm{I}_{2}\right)$

$\left(l_{3}\right)$

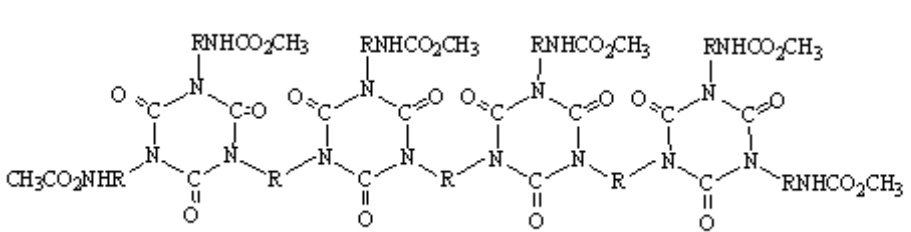

$\left(I_{4}\right)$<smiles>[R]n1c(=O)n([R16])c(=O)n(Cn2c(=O)n([R])c(=O)n([R])c2=O)c1=O</smiles>

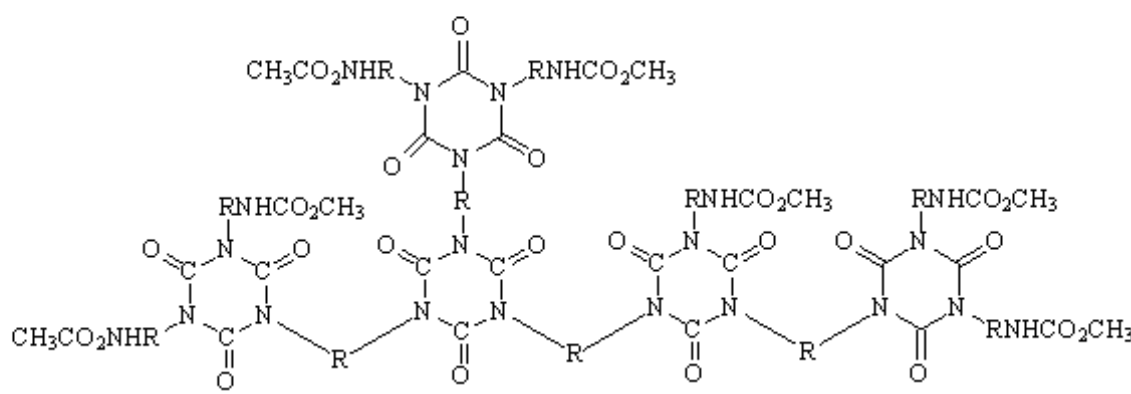

$\left(I_{4}^{\prime}\right)$

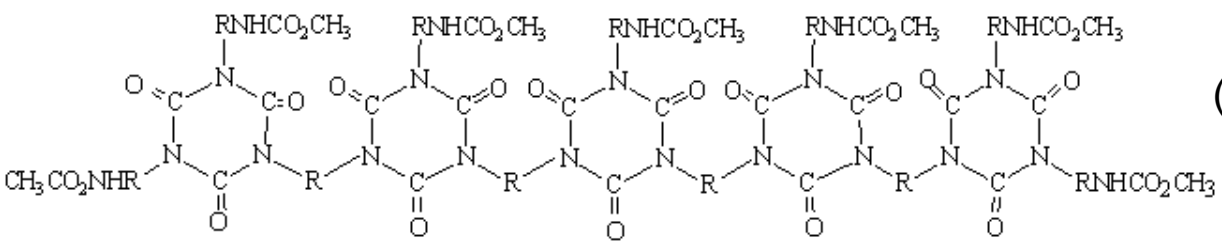

Scheme 3
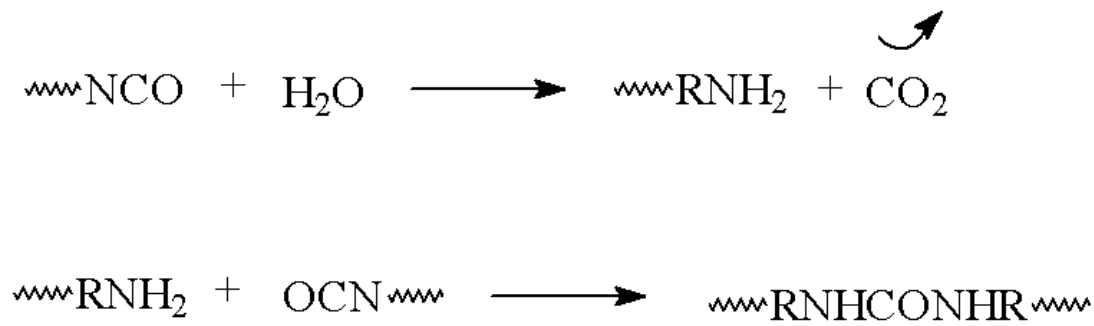

Scheme 4 
Thus, MALDI analysis allows the identification of the four fractions as oligomers of IPDI isocyanurate and we can notice that the chromatographic peaks from SEC separation correspond to pure monodisperse fraction except fraction D. Consequently quantification can only be obtained with SEC analysis using refractive index response. The refractive index $\left(n_{20}^{\mathrm{D}}\right)$ of each constituent, presented in Tab. 2, was calculated using the Van Krevelen additive group contribution model [5]. The composition of the IPDI isocyanurate was then determined by using the peak areas after deconvolution for peaks 2 to 5 . The results are the average of three measurements. According to these results, the molecular weight of the neutralized isocyanurate and of the isocyanurate, as well as its isocyanate functionality can be calculated:

Neutralized isocyanurate (NI): $\quad \bar{M}_{n N I}=\frac{1}{\sum \frac{w_{i}}{M_{i}}}=878$

$$
\bar{f}_{n}=\bar{M}_{n N l} \sum \frac{w_{i}}{M_{i}} \cdot f_{i}=3.24
$$

Isocyanurate (I):

$$
\begin{aligned}
& \overline{M_{n I}}=\bar{M}_{n N I}-\bar{f}_{n} M_{\mathrm{CH}_{3} \mathrm{OH}} \\
& \overline{M_{n I}}=878-3.24 \times 32=775
\end{aligned}
$$

Tab. 2. Quantification of the different components of the modified isocyanurate

\begin{tabular}{cccccc}
\hline Isocyanurate & $\begin{array}{c}\text { Isocyanate } \\
\text { functionality }\left(f_{i}\right)\end{array}$ & $n_{20}^{\mathrm{D}}$ & $\begin{array}{c}\text { SEC } \\
\text { signal }\end{array}$ & $\begin{array}{c}\text { Area } \\
\text { in wt.-\% }\end{array}$ \\
\hline $\mathrm{I}_{1}$ & 3 & 1,4897 & 1 & 8862 & 71 \\
$\mathrm{I}_{2}$ & 4 & 1,4937 & 2 & 2505 & 19 \\
$\mathrm{I}_{3}$ & 5 & 1,4954 & 3 & 946 & 7 \\
$\mathrm{I}_{4}, \mathrm{I}_{4}$, & 6 & 1,4964 & 4 & 328 & 2 \\
$\mathrm{I}_{5}, \mathrm{I}_{5}$, & 7 & 1,4970 & 5 & 139 & 1
\end{tabular}

These values clearly show the presence of compounds with high NCO content $(f>3)$ but also that the main product is the trimer, $\bar{f}_{n}$ being very close to three. The NCO weight percentage was then determined as follows: $\% \mathrm{NCO}=\frac{42 \times \overline{f_{n}}}{775} \times 100=17.6$. This was also determined by classical back titration with dicyclohexylamine [6]. In that case, a slightly lower value of $16,5 \pm 0,5 \%$ was obtained and close to the expected value $16 \pm 1 \%$. One can think that some isocyanate functions of oligomers are less accessible for dicyclohexylamine than for methanol.

The association of SEC experiments and a MS technique led to the identification and quantification of the different species present in IPDI isocyanurate. Nevertheless, it is not possible to differentiate $\mathrm{I}_{4}$ from $\mathrm{I}_{4}$ and $\mathrm{I}_{5}$ from $\mathrm{I}_{5}$. Moreover, we have assumed that SEC signal 4 (Fig. 1) corresponds to $I_{4}$ and $I_{4}$, and SEC signal 5 to $I_{5}$ and $I_{5}$. Although two distinct peaks are observed and even if an isocyanurate group is large enough to notably increase the volume between nonamers and undecamers, it could be still possible that the hydrodynamic volumes of the different isomers are roughly 
equivalent and thereby could affect the SEC results. However, as it concerns only a few percents, no effect on the final result can be expected.

The composition for IPDI isocyanurate was found fairly different from the HDI isocyanurate one ( $80 \%$ trimer, $10 \%$ pentamer, ...) [4]. This is probably related either to a different synthesis or to the unequal reactivity of IPDI's isocyanate groups [7].

It is noteworthy to compare the carbonyl integrations $\mathrm{C} 11$ and $\mathrm{C} 12$ in the quantitative ${ }^{13} \mathrm{C}$ NMR spectra of neutralized IPDI and neutralized IPDI isocyanurate (Fig. 3). Indeed, peaks $\mathrm{C} 11$ and $\mathrm{C} 12$ correspond to free NCO functions and the chemical shifts of their methyl urea derivatives are beyond 155 ppm. In IPDI, signals C11 and C12 have the same integrations. In the IPDI isocyanurate spectrum, one can observe first the presence of two equivalent peaks at $150 \mathrm{ppm}$ assigned to the carbonyl in the isocyanurate cycle. These two peaks are already mentioned by $\mathrm{Ni}$ [4] in the case of HMDI isocyanurate. Moreover, beyond $155 \mathrm{ppm}$ the ratio C11/C12 is close to 2 showing that isocyanurate formation occurs preferentially on the primary isocyanate group (C12).

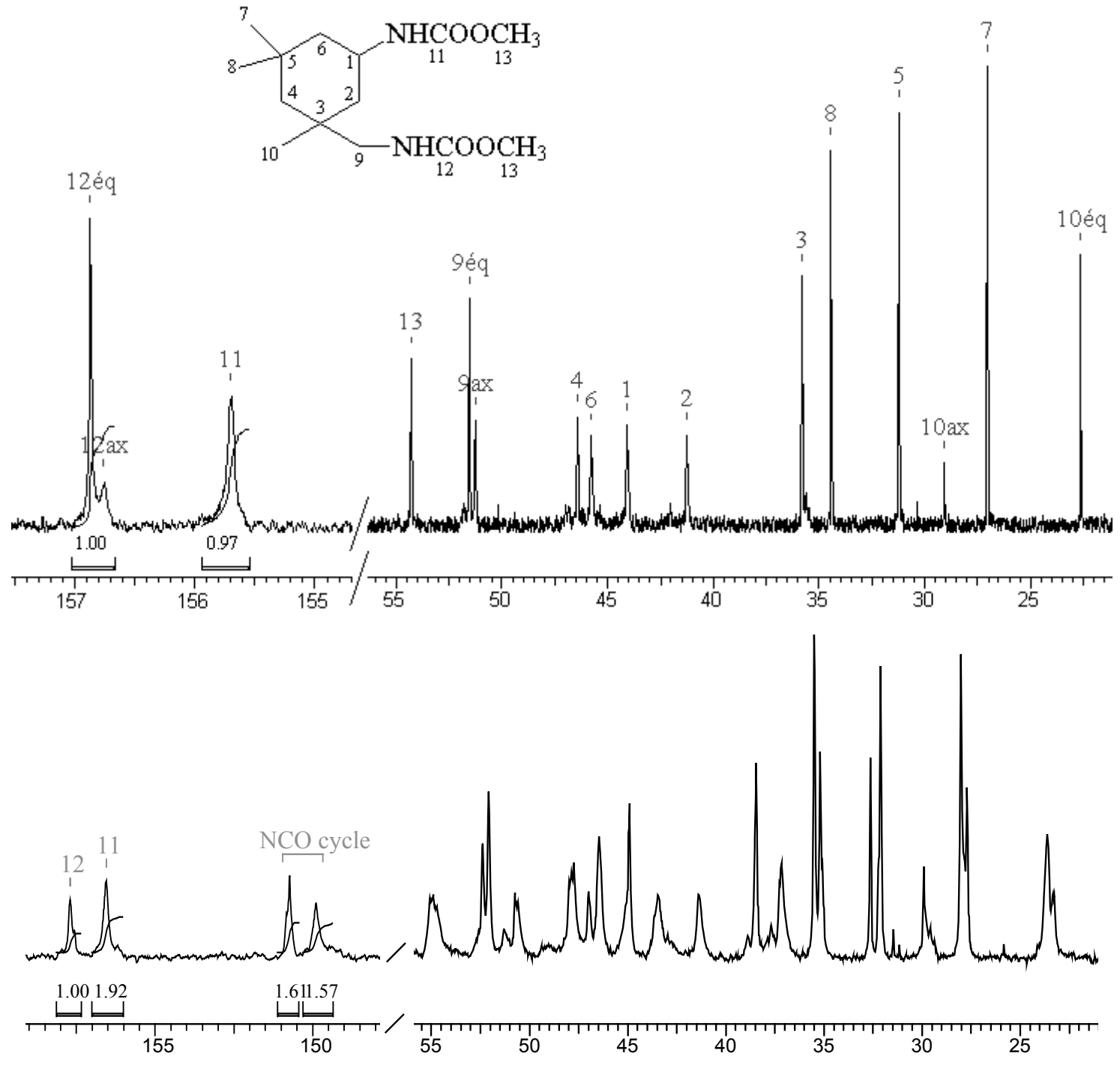

(a)

Fig. 3. NMR spectra of neutralized IPDI (a) and neutralized isocyanurate (b) in $\mathrm{CDCl}_{3}$. (a): Assignments according to ref. [2] 


\section{Conclusion}

By using MALDI-TOF MS and SEC analytical techniques we have identified and quantified the different components of an IPDI polyisocyanate currently used in the coating industry. Isocyanate trimer $(71 \%)$ and pentamer $(19 \%)$ are the two main components. Higher homologues until tridecamer were identified. These results are highly important because the chemical structure of a polyisocyanate acts directly on the structure of the resulting polyurethane and consequently on its properties. Moreover, one may expect that this IPDI isocyanurate will probably lead to complex isocyanurate - polyol kinetic systems in polyurethane chemistry.

Acknowledgement: The authors wish to thank Mr Hassan Oulyadi, Institut de Recherche en Chimie Organique Fine, UMR CNRS 6014, Université de Rouen, 76821 - Mont St Aignan Cedex (France), for NMR experiments.

[1] Disteldorf, J.; Hückel, W.; U.S. Pat. 1984, 4,469,867.

[2] Désilets, S.; Villeneuve, S.; Laviolette M.; Auger, M.; J. Polym. Sci., Part A: Polym. Chem. 1997, 35, 2991.

[3] Hatada, K.; Ute, K.; Oka, K.; Pappas, S. P.; J. Polym. Sci., Part A: Polym. Chem. 1990, 28, 3027.

[4] Ni, H.; Aaserud, D. J.; Simonsick, W. J., Jr.; Soucek, M. D.; Polymer 2000, 41, 57.

[5] Van Krevelen, D. W.; "Properties of polymers", $3^{\text {rd }}$ edition, Elsevier, Amsterdam 1997.

[6] Couvercelle, J.-P.; Bailleul, V.; Bunel, C.; Macromol. Symp. 2000, 151, 347.

[7] Cunliffe, A. V.; Davis, A.; Farey, M.; Wright, J.; Polymer 1985, $26,301$. 